\title{
Assessment of Promotional Strategies and Market Orientations on Jordanian Islamic Bank Performance
}

\author{
Ayed Al Muala ${ }^{1}$ \\ ${ }^{1}$ Faculty of Administrative and Financial Sciences, Zarqa University, Zarqa, Jordan \\ Correspondence: Ayed Al Muala, Faculty of Administrative and Financial Sciences, Zarqa University, Zarqa, \\ Jordan.
}

This research is funded by deanship scientific research and graduate studies in Zarqa University, Jordan.

Received: October 1, 2018

Accepted: December 10, 2018

Online Published: December 22, 2018

doi:10.5539/ijef.v11n1p109

URL: https://doi.org/10.5539/ijef.v11n1p109

\begin{abstract}
This study examined and observed connections between the influences of promotional strategies (PSs) and global market orientations (MOs) on the performance of Jordanian Islamic Bank. A survey was conducted using questionnaires, which were distributed to the employees of Jordanian banks. The banks of interest to this study are those that have adopted e-business. Questionnaire survey results corroborate that Jordanian bank employees should adopt MOs and PSs to realize strong bank performance (BP). The results also suggest an analysis on the influence of the sources of value creation on e-business and BP. The findings of the study are expected to contribute to the continued debate on e-business in the contemporary banking industry.
\end{abstract}

Keywords: promotional strategies, global market orientations, Islamic bank performance, Jordan

\section{Introduction}

The banking industry is considered an important sector of the economy. Some factors influence the performance of the industry, such as global market orientations (MOs) and promotional strategies (PSs). The developing world has begun to witness extraordinary advancements in information technologies that have been associated in service industries, including the banking industry. Therefore, service quality has experienced a notable increase. Over the deployment of information technology products, such as Internet banking, electronic payments, security investments and information exchanges, commerce banks and other financial establishments have been able to support organizational efforts in creating quality, fast and cheap processes and deliver high-quality services to customers (Berger, 2003). Whitten, Bentley, and Dittman (2004) asserted that "information is an interacting procedure of people, data, process and information technology to collect, process, store and deliver the required information to support business", and its specific functions include reaching good insights into the basic nature for information processes. The discussion presented above indicates that the information system contains groups, data, processes and technologies that work together via a process of accumulating, storing and delivering information output required to boost and speed up the decision-making process (Whitten et al., 2004).

Furthermore, human dimensions consider multiple challenges on marketing activities in terms of attitudes of individuals, groups and organizations. However, under technological acceleration, the marketing process has become compound. The rapid information revolution has brought transformation in the local, regional and international levels. The dynamism brought about by the market has quickly imposed tough conditions on marketers and producers, whereas the bargaining power now tends to favor the market factors. In this situation, production and marketing factors must be condensed to enhance marketing performance. However, the needs and desires of individuals should be achieved to reach customer satisfaction (Kittler, 2009). Towards this ends, marketing embraces a quantity of promotional mix to reach its objectives. An organization can reach out its customers by using the five components of promotion mix, namely, advertising, sales promotion, personal selling, public relations and direct marketing. As the financial sector continues to employ promotion mix, the growth and success of the sector rely on how it works on the actual marketing management of financial services (Czinkota \& Ronkainen, 2004).

The value and significance of information technology to bank performance (BP) is highly important. However, 
the lack of information technology and communication negatively affects the success of the banking industry and enlarges the role of the banking sector in the Jordanian economy. Therefore, efforts should be focused on the banking service environment similar to that of Jordan efforts among academic scholars to offer a general approach to e-business value creation.

Currently, the observed issues are as follows. First, comprehension about how the value is shaped in e-business is limited. Second, no verified framework that combines all relevant concepts in a practical way is available. Therefore, $t$ this study aims to contribute to the literature by developing an enhanced framework that is capable of explaining the value creation of e-business in the banking sector. The value of such a framework is twofold. First, it has the potential to benefit research in e-business. Second, it can greatly assist in eliminating confusion as to where a bank should focus its e-business strategies and investments for optimum organizational performance. Despite this need, most available research efforts on the understanding of e-business innovation have focused on the adoption decision and measures, such as "intent to adopt" and "adoption versus non-adoption" (David, 2003). Thus, the current challenge of the banking industry requires a view on e-business diffusion, use and value from a multistage process. Such process starts at the adoption stage and extends to usage and value creation (Kittler, 2009; David, 2003). In addition, a few studies on the BP issues of MO and empirical PS have already been conducted on the literature, but no evidence to gauge e-business usage and its impact on $\mathrm{BP}$ is available. This situation is attributable to the lack of evolving measures and collecting data (Itching chink, 2002). To date, most of the contents reported in the previous study rely heavily on case studies and anecdotes, and few empirical research are available to determine scales that can be used in measuring e-business or gauge their impact on BP. Hence, considerable studies in MO and PS with e-business are still lacking in the banking sector.

\section{Literature Review}

Zhu et al. (2004) developed a relevant model of e-business, which is designed to evaluate the value of e-business at the organization level. Six hypotheses form the nucleus of the model, and the model identifies technology factors that may affect the value creation of an e-business. The model was based on the technology-organization-environment framework, which contained the following factors: technology competence, organizational factors (firm scope and size) and environmental context. These components were investigated and applied to e-business by surveying a sample size of 3,100 European firms (Zhu, Kraemer, \& Xu, 2003). The model is suitable to be adopted in this study and measure of e-business in relation to the banking sector.

Nevertheless, a PS is designed to focus on the nature of the services that are promoted in e-business (Kristina, 2006). Kristina (2006) argued that advertisers should seek a narrative approach to communicate service experience rather than a logical, argumentative approach. In addition to this approach, the author urged that location convenience, speed of service, competence and friendliness of bank personnel should be given topmost priority to achieve maximum value in banking services (Laroche, Rosenblatt, \& Manning, 1986). Meidan (1976) surveyed the site element in banking services. The findings of the study validate that approximately $90 \%$ of the respondents were employed either at a branch close to their residence place or nearest to their work. The importance of convenience to the level of banking patronage has led some research to generalize that service marketing is more challenging than advertising tangible products (Ray \& Suchetana, 2006). Thus, promotional and marketing strategies of a bank should focus on consumer sovereignty, attitude, responsiveness and personal skills of bank staff; revitalizing the marketing department; top management support to the marketing department; and participation of marketing personnel in key bank decisions (Kumar, 1991).

Itching chink (2002) examined MO as an antecedent of small business performance. The study was designed to measure the magnitude of the relationship between market patterns and performances. The findings in this study are twofold: a positive relationship exists between MO and performance in small businesses, which is due to the nature and size of the positive roles of performance in the banking service. The sample population of this study was from Taiwan. This outcome motivated the author of this study to suggest that various marketing factors should be researched. In addition, the need to improve small businesses to suit the necessities of market customers and competition was properly stressed. In addition, Pellham (2000) investigated the marketing performance and growth of small industrial businesses in the USA. Its aim was to examine the level of the link between the performance of $\mathrm{MO}$ and growth in sales and marketing share. The results of the study verified that the US industry businesses in all sectors depend on various orientations as strategic items to the market. The result also confirmed that the relationship between $\mathrm{MO}$ and selling ability was significantly positive. Furthermore, previous studies asserted the market factors as predictors of market performance and recommended to pay attention to small firms to increase the efficiency of sales. The role of market factors on distinguishing 
products can increase the organization capability to reach a competitive advantage through its products. Researchers argue that the study of the market (customers and competitors) is analytical and dependent on experience and knowledge (Li WaKalntson, 1998; Pellham, 2000).

Customer orientation, research, social and ethical responsibility and profitability are essential elements that modern market is based on (Malaya, 2004). These perspectives are appropriate to all types of banking services containing emerging MOs in Islamic banks. In line with this vision, the administration orientation determines policies that can update and develop policies towards customers. It has become the vital and main objective of the organization. The administration can utilize resources and capabilities available in the organization to consequently design goals and struggles that should be taken into consideration in its long- or short-term policies. In addition, in the case of Jordan, the administration of the Islamic banks depends on consumers as the main core of market performance. However, the administration and employees require orientation. Employees and administration have responsibilities to understand the requirements, desires and wants of customers. The commitment and loyalty of customers can be increased towards banking products through orientations, and the degree of satisfaction can also be increased towards banking administration, employees and banking service (Al-Dmour, 2004).

Competition orientation is another issue in contemporary marketing and banking services. Mahmud (2014) described competitor form as the secondary chance for the performance enhancement of the Jordanian banks as it is in another habitation. The evolution of globalization and technology has equipped Jordanian banks with the ability to promote and distribute products worldwide. This evolution has caused the expansion to keep up in the pace of new customer needs and desires, which are determined as the sources of making new constraints on banks towards MO through competitors. The competitive market and the development of additional benefits are challenges that can be achieved by customers under competitive advantages.

\section{$2.1 B P$}

$\mathrm{BP}$ is the term referring to an index that implies whether a bank has been successful within a trading period and has reached its objectives. Arguably, financial statement is a vital document that is published to provide insights of the BP. According to Rose (2001), the starting point of BP assessment is to determine whether a bank has been able to achieve the set objectives as indicated by organization and stockholders. However, bank objective set differs from one bank to another. Some banks have their own distinctive objectives, whereas some may be designed to grow fast and others inclined to set long-range growth objective. Nevertheless, some banks seem to prefer a steady state by minimizing risks and conveying the image of a sound bank but with modest rewards to their shareholders (Rose, 2001). The index of firm performance is determined by stock prices and its behavior, which is commonly, used indexes. Therefore, it is not continually reliable as a market performance indicator. The size of a bank, volume of deposit and its profitability are considered other factors that are deemed as the reliable indicators of performance. For the purpose of this study, profitability indicators, in particular, return on equity capital and return on assets, were used to measure BP. These ratios are the indicators of management efficiency and rate of returns.

However, a consensus has not been reached amongst scholars on a suitable technique of business performance indicators. Consequently, diverse performance measures, such as objective and subjective measures, in addition to financial and nonfinancial measures, were adopted across studies and resulted in a variety in MO and PO performance relationships (Murphy et al., 1996; Combs \& Crook, 2005). Unbiased data are very difficult to obtain as respondents are reluctant to release sensitive information to outsiders (Dess \& Priem, 1995). By contrast, managers are generally inclined towards providing a personal evaluation of their BP, which lacks reliability (Wiklund, 1999; Wiklund \& Shepherd, 2005). Alternatively, performance can be viewed as multidimensional in nature. Therefore, integrating various subjective and objective measures of performance is beneficial for the accurate measurement of performance (Lumpkin \& Dess, 1996; Murphy et al., 1996; Wiklund $\&$ Shepherd, 2005).

\section{$2.2 \mathrm{MO}$}

Scholars defined MO as a method of company culture and strategic position of a corporation that obtains internal and external information (Alimehmeti \& Rezart, 2017). In addition, Lewrick et al. (2011) defined it as a process of strategically gathering information and disseminating it throughout a firm. This entire process requires organizational commitment and coordination. The MO in this study refers to the procedure of organizational culture where employees are systematically and entirely committed to the continuous creation of superior customer value throughout the organization (Schalk \& Gudlaugsson, 2008).

To determine existing and potential customers, MO is considered the most important aspect for service 
companies. It creates value for an organization by focusing on enhancing the satisfaction and loyalty of customers (Favalgi, 2006; Liyun, 2008; Siddharth, 2010).

\section{$2.3 P S$}

Promotion mix or marketing communication mix is defined as the specific blend of promotion tools that the company uses to persuasively communicate customer value and build customer relationship (Kotler \& Armstrong, 2010). A promotion strategy is the direct way in which an organization communicates a product or service to its target audiences or is the name given to the combination of methods used in communicating with customers (Lakshmanna et al., 2015). The goal of promotion is to persuade the target consumer to buy or consume the product offering. Various authors agree that promotional mix includes the elements of advertising, sales promotion, public relations, personnel selling and direct marketing (Brassington \& Pettitt, 2000). In the context of this study, PS plays a role in the combination or mixing together of the promotional mix components, which consequently affect the growth of company profit, increase of market share, company situation and general organizational objectives (Faajir, 2015).

\section{Relationship of PS and MO with BP}

The relationship between MO and PS and BP has received considerable attention in the organizational and marketing literature over the last two decades. However, the magnitude of this relationship seems to vary across studies. Some studies have proved that banks adopting MO perform better than those who do not adopt MO (Wales et al., 2011; Wiklund \& Shepherd, 2003). Most studies have affirmed positive performance relationship; the strength of this relationship varies significantly across various studies and contexts (Wales et al., 2011). On the contrary, some studies have reported low correlations between MO and BP (Dimitratos et al., 2004; William \& Sinkula, 2009). Some studies have failed to find a significant relationship between MO and BP (George et al., 2001; Tang \& Koveos, 2004).

Moreover, some studies have asserted the relationship between PS and BP, which is not straightforward and is shaped like an inverted U (Tang et al., 2008). An inverted-U direction denotes that a high degree of PO is not always looked for in certain market and structural conditions (Bhuian et al., 2005). Thus, considerable variation exists in the reported relationships between $\mathrm{MO}$ and $\mathrm{PO}$ with BP. Variation in results can be attributed to factors like difference in the scales of MO, PS and BP used, difference in methodology being adopted, opinion regarding variables and different indicator components of performance measured. Therefore, we postulated the following hypotheses for the three marketing dimensions: H1a: advertising (1D) positively affects BP. H1b: 2D positively affects BP. H1c: 3D positively affects BP. In addition, H2a PSD1, H2b PSD2 and H2c PSD3 have a relationship with BP. The literature suggests that the relationship amongst MO, PS and performance is not that straight forward, but rather it is influenced by the interference of various elements of organizational and industrial environments.

This study adopted a framework from past studies, which included two independent variables, namely, PSs and global MOs, and a dependent variable, that is, BP, as shown in Figure 1.

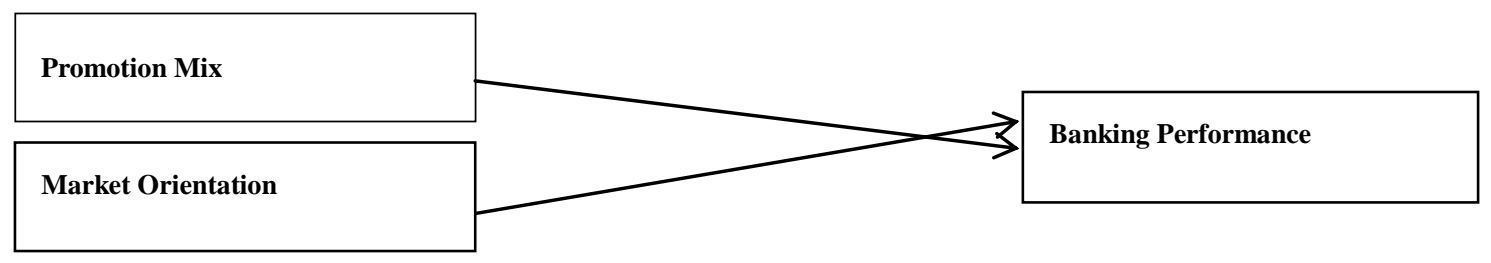

\section{Methodology}

The population of the study consisted of all Jordanian Islamic banks at Amman City. The population of the study comprised 2,571 banks in Jordan's central region encompassing three provinces, namely, Amman, Albalqa and Zarqa. The central/middle region was chosen because $45 \%$ of the bank population from the BA database is located there. Only 384 sample data from a total of 2,571 were suitable to be used. The data were analyzed using SPSS. Self-administered questionnaires were used for this study. Respondents were asked to indicate the extent of their agreement or disagreement to each statement based on a five-point numerical scale ranging from 1 ("strongly disagree") to 5 ("strongly agree"). The questions in the questionnaire were adapted and adopted from the literature. 


\section{Expected Findings}

This study considered that all hypotheses for MO and PS are acknowledged and recognized by the bank. Bank services, such as savings accounts, customer accounts, account management, new services and automated teller machines, are in need of promotion, adoption and innovation. The study is also confident to obtain positive acceptance on the effects of MO and PS on BP.

\section{Conclusion}

The main objective of this study was to determine the significant impact of PSs and MOs towards manager performance in Jordanian Islamic banks. Therefore, the important issue in this study is the impact of PSs and MOs on e-business on Jordanian banking sectors. In addition, a new framework is the impact of e-business on BP. The two approaches were applied to the study of Jordan banks that adopted e-business between 1999 and 2010. The analysis used the SPSS software to carry out the analysis of data collected for the study. Data were collected through surveys and the use of questionnaire as instrument was analyzed and presented in statistical and tabular forms. The aim was to determine the role and influence of sources of value creation on e-business value creation and BP. The outcome of the study is expected to contribute to the continued debate on e-business in the contemporary banking industry. The Jordanian banking sector, which is the sample study population, presents an interesting empirical survey as a homogenous market. Jordan is one of the regionally leading countries when it comes to investment in national IT infrastructure that is available for online services. In addition, Jordanian populations have high motivation and ability to conduct online transactions, which is one of the highest in the region.

\section{References}

Al-Dmour, H. (2004). Market Services. Amman, Jordan: Dar Weal for publication.

Berger, A. (2003). The economic effects of technological progress: Evidence from the banking industry. Journal of Money, Credit, Banking, 35(2), 141-176. https://doi.org/10.1353/mcb.2003.0009

Berkowitz, E., Kerin, R., Hartley, S., \& Rudelius, W. (2000). Marketing (6th ed.). Boston, Irwin.

Bhuian, S. N., Menguc, B., \& Bell, S. J. (2005). Just entrepreneurial enough: The moderating effect of entrepreneurship on the relationship between market orientation and performance. Journal of Business Research, 58, 9-17. https://doi.org/10.1016/S0148-2963(03)00074-2

Channon, D. (1985). Bank Strategic Management and Marketing. Biddles Ltd, Guildford and King's Lynn.

Czinkota, M., \& Radebaugh, L. (2004). International Business: Environments and Operations (9th ed.). Upper Saddle River. NJ.

David, W., \& Nigel, F. (2003).Strategic Market (7th ed.). McGraw Hill Irwin, USA.

Dimitratos, P., Lioukas, S., \& Carter, S. (2004). The relationship between entrepreneurship and international performance: The important of domestic environment. International Business Review, 13, 19-41. https://doi.org/10.1016/j.ibusrev.2003.08.001

Itching chink. (2002). Taiwan (market orientation in the performance of small firms).

Keltner, B. (1995). Relationship Banking and competitive advantage: Evidence from the US and Germany. California Management Review, 37(4), 45-72. https://doi.org/10.2307/41165810

Kittler, F. (2009). Market management, 11.

Kotler, P. (2003). Marketing Management (11th ed.). Prentice Hall of India-Private Limited.

Kotler, P., \& Armstrong, G. (2005). Principles of Marketing (11th ed). Pearson Education, Prentice Hall, Inc. London.

Kristina, H. (2006). A Conceptual Framework of Online Banking Services. Journal of Financial Services Marketing, 12, 39-52.

Kumar, A. (1991). Marketing Strategies in the Banking Sector. IBA Bulletin, 6, 13-14.

Laroche, M., Rosenblatt, J. A., \& Manning, T. (1986). Services used and factors considered important In selecting a Bank, An investigation across diverse demographic segments. International Journal of Bank Marketing, 4(1), 35-55. https://doi.org/10.1108/eb010771

Lewrick, M., Omar, M., \& Williams, R. L. (2011). Market orientation and innovators' success: An exploration of the influence of customer and competitor orientation. Journal of Technology Management and Innovation, 
6(3), 48-62. https://doi.org/10.4067/S0718-27242011000300004

$\mathrm{Li}, \mathrm{W}$. (1998). America (the role of market factors on products differentiation).

Lilien, G., Kotler, P., \& Moorthy, K. (2003).Marketing Models. New Delhi, Prentice Hall of India

Mahmud, A. (2014). The Impact of Market Orientation on the Performance of Islamic Banks (Case Study: Jordanian Islamic Banks). Journal of Engineering Research and Applications, 4(1), 31-42.

Malaya, N. (2004). The scientific assets of banking market (1st ed.). Amman, Jordan, Dar Weal House for publication.

Meidan, A. (1976). Branch Managers attitude on Bank objectives and operations. Proceedings of European Academy of advanced research in Marketing Conference, France, pp. 215-228.

Meidan, A. (1996). Marketing Financial Services. London Macmillan Press Ltd. https://doi.org/10.1007/978-1-349-24475-1

Nikolai, L., \& Bazlay, J. (1997). Intermediate Accounting. Ohio: South-Western College Publishing.

Owaga, O. (2002): Marketing Management Systems. Pesisu Industries, Nairobi.

Pelham. (2000). America (the market performance of the small U.S. industrial companies).

Ray, S., \& Suchetana, B. (2006).Strategizing Advertisements in Services Sector.Marketing Mastermind, 3, 23-29.

Rezart, P., \& Alimehmet, G. (2017). Market orientation, innovation, and firm Performance an analysis of Albanian firms. Journal of Innovation and Entrepreneurship, 6(8).

Rose, P. (2001). Commercial Bank Management (5th ed.). McGraw Hill Irwin.

Tang, J., Tang, Z., Marino, L. D., Zhang, Y., \& Li, Q. (2008).Exploring an inverted U shape relationship between entrepreneurial orientation and performance in Chinese ventures. Entrepreneurship Theory and Practice, 32(1), 219-239. https://doi.org/10.1111/j.1540-6520.2007.00223.x

Tang, L., \& Koveos, P. E. (2004). Venture entrepreneurship, innovation entrepreneurship and economic growth. Journal of Developmental Entrepreneurship, 9(2), 161-171.

Thuo, J. K. (2008). Principles of Marketing, A skill building approach (2nd ed.). Nairobi: Thomson Press.

Wales, W. J., Monsen, E., \& McKelvie, A. (2011). The organizational pervasiveness of entrepreneurial orientation. Entrepreneurship Theory and Practice, 35(5), 895-923. https://doi.org/10.1111/j.1540-6520.2011.00451.x

Whitten, J., Bentley, L., \& Dittman, K. (2004). System Analysis and Design Methods. New York: Mc.GrawHillk.

Wiklund, J., \& Shepherd, D. (2003). Knowledge-based resources, orientation, and the performance of small and medium sized businesses.Strategic Management Journal, 24, 1307-1314. https://doi.org/10.1002/smj.360

William, E. B., \& Sinkula, J. M. (2009). The complementary effects of market orientation and entrepreneurial orientation on profitability in small businesses. Journal of Small Business Management, 47(4), 443-464. https://doi.org/10.1111/j.1540-627X.2009.00278.x

Worthington, I., \& Britton, C. (2006).The Business Environment (5th ed.). Prentice Hall.

Zhu, K., Kraemer, K., \& Dedrick J. (2004). Information Technology Payoff in E-Business Environments: An International perspective on Value Creation of E-Business in the Financial Services Industry. Journal of Management Information Systems, 21(1), 17-54. https://doi.org/10.1080/07421222.2004.11045797

Zhu, K., Kraemer, K., \& Xu, S. (2003). E-business adoption by European firms: A cross-country assessment of the facilitators and inhibitors. European Journal of Information Systems, 12(4), 251-268. https://doi.org/10.1057/palgrave.ejis.3000475

\section{Copyrights}

Copyright for this article is retained by the author(s), with first publication rights granted to the journal.

This is an open-access article distributed under the terms and conditions of the Creative Commons Attribution license (http://creativecommons.org/licenses/by/4.0/). 